\title{
Description of the feeding preferences of triatominae in the Chagas disease surveillance study for the State of Pernambuco, Brazil (Hemiptera: Reduviidae)
}

\author{
Maria Beatriz Araújo Silva ${ }^{[1],[2]}$, Kelly Reis de Menezes ${ }^{[1]}$, Maria Clara Guerra de Farias $^{[1]}$, \\ Maria Sandra Andrade ${ }^{[1],[3]}$, Caio Cesar Alves Victor ${ }^{[1]}$, \\ Elias Seixas Lorosa ${ }^{[4]}$ and José Jurberg ${ }^{[4]}$
}

\begin{abstract}
[1]. Faculdade de Enfermagem, Universidade de Pernambuco, Recife, PE, Brasil. [2].Laboratório Central de Saúde Pública "Dr. Milton Bezerra Sobral", Recife, PE, Brasil. [3]. Programa Associado de Pós-Graduação Stricto Sensu em Enfermagem em Promoção da Saúde, Universidade de Pernambuco, Universidade Estadual da Paraíba, Recife, PE, Brasil. [4]. Laboratório Nacional e Internacional de Referência em Taxonomia de Triatomíneos, Departamento de Entomologia, Fundação Oswaldo Cruz, Rio de Janeiro, RJ, Brasil.
\end{abstract}

\begin{abstract}
Introduction: Studying the feeding preferences of triatomines is an important entomological surveillance tool, since continuous surveillance of the disease is necessary. Methods: The precipitin reaction was used to describe the feeding preferences of triatomines along with their natural infection by flagellates similar to Tyrpanosoma cruzi. Six hundred eighty-seven insects were examined, including Triatoma brasiliensis, Triatoma pseudomaculata, and Panstrongylus lutzi. Results: Sixty-nine (10\%) of 687 triatomines examined tested positive for flagellates similar to T. cruzi, and $8(1.2 \%)$ of these fed on human blood. Conclusions: This study found potential transmitters of Chagas disease both inside and outside the domiciliar environment.
\end{abstract}

Keywords: Triatominae. Food preferences. Chagas disease.

Chagas disease (CD), caused by the protist Trypanosoma cruzi and spread by triatomines, is considered a neglected disease, but it is still a serious public health problem in Brazil and Latin America. It is now becoming a global public health concern in non-endemic areas owing to human migration to developed countries and affects more than 12 million individuals. Its prevalence and distribution are closely related to environmental, socio-cultural, and political factors ${ }^{1}$.

Species that are found in environments occupied by humans and that feed on pets and domesticated animals are of great epidemiological interest ${ }^{2}$. The study of the feeding preferences of triatomines has significantly contributed to our understanding of their biology in the natural habitat and in human dwellings and of their place in the chain of transmission and perpetuation of $T$. cruzi in humans.

A study by Siqueira (1960) showed that it was possible to ascertain, using the precipitin reaction, the origin of the food of triatomines, even those that had eaten more than 120 days previously. Concentrating on knowledge of household vectors is the main strategy for preventing human infection, since treatment of CD is still partially ineffective ${ }^{3}$.

Corresponding author: Profa. Maria Beatriz Araújo Silva.

e-mail: silvamba@yahoo.com.br

Received 19 August 2016

Accepted 28 March 2017
The aim of the present study was to investigate the feeding preferences of triatomines as a tool for epidemiological surveillance of Chagas disease.

From January 2013 to January 2015, triatomines were collected within and in the vicinity of homes (chicken coops, animal pens, stone walls, fences, and rubble) in 81 municipalities of the State of Pernambuco, which includes the Metropolitan Region of Recife, Zona da Mata, the Agreste region, and the Sertão and Sertão do Rio São Francisco regions.

The insects were collected manually in homes using techniques used to address endemics in the municipalities and sent for initial analysis to entomology laboratories in their corresponding Health Management Region [Gerência Regional de Saúde (GERES)] and then to the Laboratory for Endemic Diseases, Pernambuco Central Laboratory (LABEND/ LACEN-PE). This laboratory is responsible for quality control (taxonomic identification and parasitological examination of triatomines) and works in conjunction with surveillance authorities to oversee the prevalence of CD.

All of the infected insects and $40 \%$ of the non-infected insects that tested negative for natural infection by Trypanosoma $s p$. were analyzed. When necessary, a lantern and liquid repellent (Pirisa 2\%) were used to collect the triatomines.

The triatomines were identified at the species level in accordance with Lent and Wygodzinsky ${ }^{4}$. Parasitological research was carried out using abdominal compression of the insects and subsequent parasitological studies of the (fresh) 
contents of the intestines. Identification of parasite phenotype was carried out by observation under an optical microscope, using Giemsa-stained insect feces. The natural rate of infection was obtained from entomological indicators, as outlined by the Pan-American Health Organization and the Brazilian Ministry of Health ${ }^{5}$.

For the precipitin test, the abdomen of each insect was pressed dorsoventrally, and drops of feces were deposited on strips of Klabin filter paper. The identified samples were then sent to the National and International Triatomine Taxonomy Reference Laboratory [Fundação Oswaldo Cruz (FIOCRUZ)/ Rio de Janeiro]. This material was then numbered, set aside to dry, and kept at $4^{\circ} \mathrm{C}$ until analysis. For this test, the filter paper containing the sample was submerged in saline solution $(\mathrm{NaCl}$ $0.85 \%$ ), and the eluate obtained was examined using a precipitin immunological reaction with the capillary tube technique.

The sources of blood obtained from the insects were determined by reacting the eluate of the material collected in the filter paper with antisera specific to birds, cockroaches, cattle, goats, dogs, horses, lizards, skunks, cats, humans, pigs, coatis, rodents, frogs, armadillos, and sheep, all of which are commonly found in the region. The preparation of antisera and the evaluation of their titration and specificity were carried out in accordance with Siqueira (1960) $)^{3}$.

Data analysis employed descriptive techniques with the presentation of tables and graphs using Microsoft Office Excel 2007. Exclusion criteria included incomplete data on provenance, lack of specific identification, and inability to conduct tests.

The study was approved by the University of Pernambuco (UPE) and Dr. Milton Bezerra Sobral Public Health Laboratory (LACEN-PE).

During the study period, a total of 687 triatomines were examined. The natural infection rate of flagellates similar to T. cruzi was found to be $69(10 \%)$.
Human blood was found in the contents of the intestines of $84(12.2 \%)$ insects, of which $8(1.2 \%)$ tested positive for the presence of trypanosomatids. Of the four species in which human blood was found, only Triatoma brasiliensis and Panstrongylus lutzi also tested positive for T. cruzi (Table 1).

Of the 84 triatomines with human blood in the contents of their intestines, 46 (54.8\%), were $T$. brasiliensis, followed by Triatoma pseudomaculata with $26(31,0 \%)$, P. lutzi with 10 (11.9\%) and Panstrongylus megistus with 2 (2.4\%).

Triatoma brasiliensis, Triatoma pseudomaculata, and Panstrongylus lutzi predominated among the insects collected (Table 2).

The content of the intestines of the 687 triatomines that reacted to the antisera provided the following source data: birds $(28 \%)$, rodents $(22 \%)$, dogs $(10.7 \%)$, goats $(9.2 \%)$, human blood $(9.1 \%)$, skunks $(9 \%)$, cats $(3.3 \%)$, cockroaches $(2.9 \%)$, horses $(1.2 \%)$, lizards $(1.1 \%)$, cattle $(0.9 \%)$, frogs $(0.9 \%)$, pigs $(0.7 \%)$, armadillos $(0.7 \%)$, and coatis $(0.2 \%)$.

Sixteen animals were found to be food sources, and only three of these - skunks, armadillos, and coatis - do not live in the proximity of human environments and are considered wild.

The preferred food source for males was birds (29\%) and rodents $(22 \%)$. Similar results were found for females, although in different percentages, with a lower figure for birds (27\%) and a higher one for rodents $(23 \%)$.

The study of food source diversity and the precipitin test also revealed the presence of multiple food sources for triatomines, with 56 combinations of two or three sources found. Forty-one (73\%) of these combinations contained two sources and $15(27 \%)$ contained three. Of the combinations of two sources, $22 \%$ were bird and rodent, and 13\% were bird and human blood.

Triatoma brasiliensis had the largest number of food sources, feeding on $14(87.5 \%)$ of the 16 sources studied, followed by P. lutzi with $13(81.3 \%)$ and T. pseudomaculata with 12 (75\%).

TABLE 1

Anthropophilia by sex and location of synanthropic triatomines in the State of Pernambuco, 2013-2015.

\begin{tabular}{|c|c|c|c|c|c|c|}
\hline Species & $\begin{array}{c}\text { Triatomines } \\
n^{\circ}(\%)\end{array}$ & Inside* & Surrounding** & Male & Female & $\begin{array}{c}\text { Natural } \\
\text { infection rate } \\
(+)\end{array}$ \\
\hline $\begin{array}{l}\text { Triatoma } \\
\text { brasiliensis }\end{array}$ & $46(54.8)$ & $26(31.0 \%)$ & $20(23.8 \%)$ & $18(21.4 \%)$ & $28(33.3 \%)$ & $4(4.8 \%)$ \\
\hline Panstrongylus lutzi & $10(11.9)$ & $\begin{array}{c}8 \\
(9.5 \%)\end{array}$ & $2(2.4 \%)$ & $6(7.1 \%)$ & $04(4.8 \%)$ & $4(4.8 \%)$ \\
\hline $\begin{array}{l}\text { Panstrongylus } \\
\text { megistus }\end{array}$ & $2(2.4)$ & $\begin{array}{c}2 \\
(2.4 \%)\end{array}$ & 0 & $2(2.4 \%)$ & 0 & 0 \\
\hline
\end{tabular}

*Inside the home. **Surrounding the home. 
TABLE 2

Numbers of triatomines and feeding preferences by species in the state of Pernambuco, 2013-2015.

\begin{tabular}{llcc}
\hline Species & Number (\%) & Natural infection rate & Feeding preference \\
\hline Triatoma brasiliensis & $325(47.3)$ & 32 & $\begin{array}{c}\text { Bird (132), Rodent (91), Skunk (46) } \\
\text { Dog (43), Goat (30), Human blood (46) }\end{array}$ \\
\hline Triatoma pseudomaculata & $208(30.3)$ & 12 & Bird (72), Rodent (66), Skunk (20), Dog (35) Goat (32), Human blood (26) \\
\hline Panstrongylus lutzi & $111(16.2)$ & 22 & Bird (41), Rodent (36),Skunk (15), Dog (16) Goat (17), Human blood (10) \\
\hline Panstrongylus megistus & $31(4.5$ & 2 & Bird (12), Rodent(12), Skunk (01), Cat (2) Dog (3),Goat (3), Cockroach \\
(2),Human blood (2)
\end{tabular}

The present study revealed significant numbers of triatomines in the residences studied. T. brasiliensis, T. pseudomaculata, and $P$. lutzi accounted for the highest percentages of the total number of triatomines found inside residences. The level of adaptation of triatomines to human housing needs to be precisely evaluated to allow for the design of effective vector control strategies. Ensuring that the surroundings of residences have a low rate of infestation may constitute a barrier to the entry of these triatomines into homes ${ }^{6,7}$.

According to the present study, among the 687 triatomines studied in the State of Pernambuco, T. brasiliensis, T. pseudomaculata, and P. lutzi were the most commonly found species. This concurs with other studies that describe the Northeast region of Brazil, in the context of the epidemiology of $\mathrm{CD}$, as the epicenter for the dispersion of two species of triatomine that are difficult to control: T. brasiliensis and T. pseudomaculata ${ }^{6}$.

A study conducted in several Northeast states, including Pernambuco, showed a predominance of $T$. brasiliensis and T. pseudomaculata in the surroundings of residences. However, research carried out in the State of Piauí in 2008 revealed $T$. brasiliensis to be the most prevalent inside the home, corroborating the results of the present study, in which these two species were the ones most commonly found indoors ${ }^{8-10}$.

Triatoma brasiliensis is widely distributed in Bahia and Pernambuco, principally in caatinga regions. It is frequently found in residences and is considered the most important vector in the Northeast of Brazil ${ }^{11}$. It is the third most common species in Bahia and frequently serves as a vector for Chagas disease. The results of the present study underline its importance as a vector in the transmission of Chagas disease, since this species has a wide geographical distribution throughout the State of Pernambuco. T. brasiliensis is thus the species most commonly found in the home and has the second highest rate of natural infection by flagellates similar to T. cruzi, being the most prevalent species in the state.
Although triatomines are known to feed on the blood of vertebrate hosts, recent studies have shown that the nymphs of triatomines develop normally when fed on the hemolymph of Blaberidae $^{12}$. These authors argue that feeding on hemolymph is probably a means of survival that triatomines adopt when little blood is available. This may be confirmed by the present study, in which the presence of Blaberidae hemolymph protein was detected in the contents of the intestines of some specimens of T. brasiliensis, T. pseudomaculata, P. lutzi, and P. megistus.

The present study identified multiple feeding sources in the case of $P$. megistus. The presence of 10 distinct food sources was found, in accordance with data in the literature showing that it feeds on birds, humans, dogs, cats, marsupials, rodents, cattle, goats, pigs, and other animals ${ }^{9,13}$. Like P. megistus, $P$. lutzi may be considered a species with multiple food sources, since 13 different sources were found.

The mixed food sources suggest that the species identified in these studies move between wild and domestic environments and are found both indoors and outdoors in the case of the latter. They have a high rate of infection by trypanosomatids $(10 \%)$ and therefore pose an imminent risk of infecting humans.

In the case of $P$. lutzi, Neiva \& Pinto (1923) found that despite the frequent presence of dogs in the homes studied, no specimens tested positive for this food source, strengthening the hypothesis that these insects prefer to feed on wild fauna. The present study, however, revealed large numbers of this species in residential environments, since $92.8 \%$ of specimens were found inside homes and fed on the blood of domestic and synanthropic animals.

Epidemiological studies show that domestic birds play an important role in the transmission of Trypanosoma cruzi to human beings because, although unaffected by the disease, they serve as a source of food for triatomines in the areas surrounding homes, enabling abundant populations of these vectors to develop in the proximity of human beings and serving as a link between the wild and the domestic environment ${ }^{14}$. Even in the case of multiple food sources, birds were the preferred source, along with rodents and human blood. 
A previous parasitological study conducted in Pernambuco found that $8.8 \%$ of triatomines were naturally infected by flagellates morphologically similar to T. cruzi, and $91.3 \%$ were found inside homes ${ }^{9}$. The present study produced similar figures, with a rate of natural infection of around $10 \%$ with $79.7 \%$ found in homes.

According to Martins $(1968)^{15}$, the endemic infection of humans by Chagas disease is made possible when there are domiciliated triatomines with easy access to humans, providing them with a source of blood and allowing them to transmit the T. cruzi protozoan. It is important to note this, since, in the present study, most specimens were collected inside homes $(63.8 \%)$, with a far smaller portion collected in the surroundings of homes (36.2\%). This demonstrates the synanthropism of these vectors, which live closer to humans and make it easier to infect them with Chagas disease on an endemic scale in these regions.

Studying the feeding sources of triatomines may shed light on the eco-epidemiological aspects of transmission of CD and its wild and domestic cycles, underlining the importance of maintaining entomological surveillance, providing an epidemiological study tool, and improving the quality of information available on the control and prevention of this endemic disease.

This study showed that several specimens of triatomines, potential transmitters of $\mathrm{CD}$, are present in the human environment, inside and outside homes, of almost all municipalities of the state, reinforcing the need for continuous surveillance of the epidemiology of the disease and the entomology of vectors of the disease.

\section{Acknowledgments}

The authors would like to thank Central Public Health Laboratory Lacen/LabendPE technicians Odivânea Maia da Costa and Cecília Maria do Nascimento Rocha for carrying out the parasitological examinations and the Fundação de Amparo à Ciência e Tecnologia do Estado de Pernambuco (FACEPE).

\section{Conflict of interest}

The authors declare that there is no conflict of interest.

\section{Financial support}

Fundação de Amparo à Ciência e Tecnologia do Estado de Pernambuco (FACEPE).

\section{REFERENCES}

1. Organização Mundial da Saúde. Control de la Enfermedad de Chagas. Washington: OMS; 1991. 98p.
2. Freitas SPC, Lorosa ES, Rodrigues DCS, Freitas ALC, Gonçalves TCM. Fontes alimentares de Triatoma pseudomaculata no Estado do Ceará, Brasil. Rev Saúde Pública. 2005;39(1):27-32.

3. Siqueira AF. Estudo sobre a reação da precipitina aplicada a identificação de sangue ingerido por triatomíneos. Rev Inst Med Trop de São Paulo. 1960;2:41-53.

4. Lent H, Wygodzinsky PW. Revision of the Triatominae (Hemiptera, Reduviidae) and their significance as vectors of Chagas' disease. Bull Am Mus Nat Hist. 1979;163:123-520.

5. Organización Panamericana de la Salud (OPAS). Guia para muestreo en actividades de vigilancia y control vectorial de la enfermidad de Chagas. Ginebra: OPAS; 2003. 46p.

6. Silveira AC, Vinhaes MC, Lira E, Araújo E. O Controle de Triatoma brasiliensis e Triatoma pseudomaculata. Brasília: Organização Pan-Americana de Saúde; 2001. 86p.

7. Dias-Lima AG, Sherlock IA. Sylvatic vectors invading houses and the risk of emergence of cases of Chagas disease in Salvador, State of Bahia, Northeast Brazil. Mem Inst Oswaldo Cruz. 2000;95(5):611-3.

8. Silva MBA, Menezes KR, Siqueira AM, Balbino VQ, Lorosa ES, Farias MCG, et al. Importância da distribuição geográfica dos vetores da doença de Chagas em Pernambuco, Brasil, em 2012. Rev Patol Trop. 2015;44(2):195-206.

9. Silva MBA, Barreto AVMS, Silva HA, Galvão C, Rocha D, Juberg J, et al. Synanthropic triatomines (Hemiptera, Reduviidae) in the state of Pernambuco, Brazil: geographical distribution and natural Trypanosoma infection rates between 2006 and 2007. Rev Soc Bras Med Trop. 2012;45(1):60-5.

10. Braz SCM, Melo MFAD, Lorena VMB, Souza WV, Gomes YM. Chagas disease in the State of Pernambuco, Brazil: analysis of admissions and mortality time series. Rev Soc Bras Med Trop. 2011;44(3):318-23.

11. Argolo AM, Felix M, Pacheco R, Costa J. Doença de Chagas e seus principais vetores no Brasil. Rio de Janeiro: Editora Imperial Novo Milênio; 2008. 63p.

12. Ruas-Neto AL, Corseuil E, Cavalleri A. Development of rupestrian triatomines (Hemiptera, Reduviidae, Triatominae) following hemolymphagy on blaberids (Blattodea, Blaberidae) in Rio Grande do Sul State, Brazil. Entomol Vect. 2001;8:205-16.

13. Barretto MP, Siqueira AF, Pedreira de Freitas JL. Estudos sobre reservatórios e vetores silvestres do Trypanosoma cruzi. II. Encontro de Panstrongylus megistus em ecótopos silvestres no estado de São Paulo (Hemiptera, Reduviidae). Rev Inst Med Trop. 1964;6(2):56-63.

14. Gorla DE. Que características podem definir espécies/populações de triatomíneos com maior potencial vetorial? Rev Soc Bras Med Trop. 2001;34(Supl III):81-2.

15. Martins AV. Epidemiologia da doença de Chagas. In: Cançado JR, editor. Doença de Chagas. Belo Horizonte: Imprensa Oficial; 1968. p. 225-37. 